\title{
Arquivologia e Desenvolvimento
}

José Pedro Esposel

\section{O desenvolvimento, a administração e o atquivo}

$\mathrm{U}$

MA forma de participarmos, ativa e conscientemente, de uma uma ação séria em prol do desenvolvimento, consiste no exame meticuloso, na avaliação criteriosa de todos os elementos fundamentais e secundários - que constituem a sua problemá tica e influenciam o seu processamento. "A análise dos obstáculos ao desenvolvimento é parte essencial do estudo do próprio desenvolvimento. Nem prática, nem conceitualmente, é possivel separar os dois aspectos do problema; na verdade, não temos aqui dois problemas distintos, mas sim dois modos de encarar um problema único - o desenvolvimento, seu progresso global e os obstáculos diante dêle criados pelas próprias estruturas qué se desenvolvem."

Evidentemente a dinamização dos processos com vistas a um resultado que se concretize num acentuado progresso, demanda, além de uma dedicação integral e esclarecida de tôda a coletividade, uma solicitação incomum, afanosa, plena de sacrificios àqueles incumbidos, responsáveis pela administração. E não é sem razão que às preocupações por um crescimento econômico e melhoria das condições sociais, num pais em desenvolvimento, se acrescentem as medidas de organização administrativa como etapa preliminar e essencial. Evangelos John Rizos (Consultor da Organização Mundial de Saúde para a Malásia) em artigo sôbre "Desenvolvimento: A Nova Ética da Administração Pública" ("Revue Internacionale des Sciences Administratives, vol. XXI, 1965, n 4, págs. 279/288) ao interpretar o discurso do DiretorGeral da UNESCO na abertura da Conferência das Nações

1 - L. A. Costa PINto, "Sociologia e Desenvolvimento - temas e problemas de nosso tempo" - Edit. Civilização Brasileira S. A. Rio de Janeiro - 1963 - pág. 86 
Unidas para a Aplicação da Ciência e da Tecnologia em Benefício das Áreas Menos Desenvolvidas, destaca que "a qualidade da administração pública num país em desenvolvimento não é uma obsessão quixotesca mas serve de muitas maneiras para elevar ao máximo de sua capacidade as metas do desenvolvimento ou, ao contrário, para negá-las." $\left({ }^{2}\right)$ Justamente para dotar a nação dos instrumentos e condições propícias a um inadiável desenvolvimento é que o Govêrno Federal vem de estabelecer, em decreto de $n^{\circ}$ 200-67, a Reforma Administrativa.

Ressaltada, embora sucintamente, a relevante importância desempenhada pelas administrações nos processos de desenvolvimento, examinemos no contexto daquelas as funções dos arquivos.

Inicialmente pode-se afirmar, com tôda validade, que "as instituições arquivisticas são um eficaz instrumento administrativo do govêrno." ( $\left.{ }^{3}\right)$ E, sem exagerar, o mais destacado arquivista norte-americano, Dr. Theodore R. Schellenberg, acrescenta: "os arquivos, mesmo os mais antigos, sempre são necessários nas tarefas de um govêrno. Refletem as origens e o crescimento dêste e são a principal fonte de informações de tôdas suas atividades. Constituem os instrumentos administrativos básicos com os quais se realizam as tarefas do govêrno. Contém as provas dos assuntos legais e financeiros que devem ser conservadas para sua proteção. Abrangem o grande fundo de experiência oficial que necessita o govêrno para dar continuidade e consistência a suas ações, para tomar determinaçôes políticas e encaminhar problemas ou procedimentos de organização econômica e social. Em resumo, são as bases sôbre as quais se assenta a estrutura governamental." ( $\left.{ }^{4}\right)$ Compreendemos, então, que se impõe um conveniente e muito intimo entrosamento do arquivo com todos os aspectos do complexo administrativo. O passado, em tôda a sua plenitude, deve estar à disposição dos administradores auxiliando-os - a sunerar os problemas atuais. Exercem os arquivos o papel de conselheiros da administração e a ela fornecem a documentação indispensável ao seu trabalho. Lá se encontram os precedentes com os quais instruirá as suas decisões, as provas que amparam seus direitos e prerrogativas, as experiências formuladas e já testadas na solução de prublemas semelhantes no pretérito e uma multidão de assuntos documentados e valiosos, quando devidamente investigados, como subsídios de primeira ordem na melhoria das

2 - Rvistáa do Sernico Público, vol. 98, $\mathrm{n}^{\circ}$ 3, julho-agôsto-setembro de 1966, págs. 14-16.

3 - George S. Ulibarri. "Semelhanças e diferenças entre Arquivos e Bibliotecas" - Inter-American Review of Bibliography, vol. XII, n 3 , julho-setembro de 1962, págs. 269-278.

4 - Theodore R. Schellenberg, "Modern Archives Principles and Techniques - Melbourne e Chicago - 1956. 
medidas administrativas. Se não bastassem tais argumentos na esfera da rotina dos serviços ainda nos lembrariamos do papel decisivo dos arquivos na comprovação da honestidade e lisura das gestões governamentais. Quando são levantadas dúvidas ou pairam indagações concernentes a atitudes assumidas por governantes no trato das coisas públicas, em que lugar, preliminarmente, encontrarão as Comissões de Inquérito e os grupos de devassa, os elementos elucidativos para incriminar ou incentivar as autoridades envolvidas? No arquivo estará adormecida tôda a atividade desenvolvida no período e pronta para, despertada, esclarecer as deliberações tomadas, prestar as contas devidas, explicar as opções adotadas. Tal justiça não se exerce ùnicamente para satisfação aos contemporâneos. No futuro imprevisivel ela se revelará às novas gerações para aclarar, senão a lisura com que foram conduzidos os atos oficiais, a própria atuação, suas contribuições ao progresso ou, ao contrário, a interrupção em uma fase de expansão, a estagnação de uma politica de crescimento, enfim, pela comparação de muitos e sucessivos períodos governamentais, aquêles que verdadeiramente se destacaram por seu dinamismo e os outros que se revelaram como inoperantes e responsáveis por regressões e entraves ao desenvolvimento.

Chegamos, então, a um outro aspecto dos arquivos, peculiaridadc extraordinária, metamorfose que garante seu valor e iustifiça sua conservação indefinida. Despido de sua utilidade imediata, desligado das atribuições inerentes a um dos principais instrumentos da administração vai, a massa documental adquirindo um gradativo valor histórico, até se tornar a principal fonte de reconstituição. "Quanto mais unido está o documento à vida prática da administração, tanto mais afastado está do interêsse cultural-histórico e quanto mais perde o interêsse administrativo se aproxima em troca ao histórico até confundir-se por completo com êste." (5)

Já se disse que uma nação sem arquivos é uma nação sem passado. Ainda mais: "o cuidado devotado por um país a preservacão dos monumentos de seu passado pode servir de medida verdadeira, do grau de civilização que êle atingiu. Entre tais monumentos e ocupando o primeiro lugar em valor e imporância pstão os arquivos públicos, nacionais e locais." ${ }^{6}{ }^{6}$

Consumada a sua principal missão como peça fundamental na engrenagem administrativa e exaurida sua utilização imediata

5-Aurelio TANODI, "Manual de Archivologia Hispanoamericana - Teorias e Principios" - Universidade Nacional de Cordoba - 1961. påg. 71 .

6 - CH:RLEs M. AndREWs, eminente historiador americano citado por T. R. SchelleknBeRg in "Importância dos Arquivos Públicos" - Arquivo Nacional, $\mathrm{n}^{\circ} 10-$ Rio de Janeiro, 1960, pág. 57. 
assume o arquivo outra dimensão de relêvo, depositário que é do pretérito. "O reconhecimento do predomínio da função administrativa dos arquivos públicos não exclui as atividades históricas, pois a documentação conservada em um arquivo público é tôda aquela que tem valor permanente, duradouro e histórico. $\left({ }^{7}\right)$

\section{Arquivologia: noções e generalidades}

Por arquivologia compreenderemos uma disciplina auxiliar da administração e da história, que se refere a criação histórica, organização e função dos arquivos e seus fundamentos legais ou juridicos. $\left({ }^{8}\right)$

Constitui, não obstante a vetustez da história dos arquivos, uma técnica relativamente recente, em fase de consolidação de conceitos e práticas, inclusive no âmbito internacional. A sua terminologia não se acha unânimemente fixada, variando os vocábulos conforme os autores. O conteúdo abrange tudo o que se relaciona com os arquivos, podendo ser apreciado sob vários aspectos:

1 - a parte da teoria e dos conceitos gerais, isto é, assuntos relacionados com a natureza mesma dos arquivos, seus princípios, análise de suas funções e importância administrativa, histórica, jurídica, social, pedagógica, etc., estudo de suas divisões e tipos, compreensão e definição da terminologia própria, apreciação das relações com ciências e disciplinas afins caracterizando a sua posição na área da documentação e ainda a prescrição de normas sôbre o pessoal técnico e especializado e respectivas atribuições;

2 - tudo o que se refere a conservação material e restauração de documentos, a instalação dos edifícios próprios, mobiliário e setores técnicos;

3 - o conjunto de técnicas sôbre organização e administração dos arquivos (sistemas e métodos de arquivamento, ordenação, classificação, disposições para guarda do material, con* trôle de movimentação, operações de expurgo, eliminação, etc.

4 - a história dos arquivos que traça a evolução da instituição desde a mais remota antigüidade;

5 - o corpo de doutrinas legais e regulamentares, isto é, a sua fundamentação jurídica.

Apreciemos, em rápida revista, os títulos acima.

No que se refere a natureza podemos estudar o conceito de arquivo segundo a origem etimológica do vocábulo. Seria proce-

7 - José Honórıo Rodrigues, "A situação do Arquivo Nacional - Rio de Janeiro, 1959, pág. 13-14.

8-Aurélio TANOdI, op. cit., pág. 42. 
dente do grego e muito provàvelmente da raiz "archeion", sede ou palácio do magistrado, casa do arconte, que guardava junto a si os documentos relacionados com suas atividades e funções. Dai êste nome ter sido empregado também para os depósitos de documentos naquela época. Passando para o latim tomou a forma de "arcivum", "archivum", "archivium", transmitindo-se posteriormente a muitas linguas européias e até nós. Atualmente, empregamos o vocábulo com várias significações:

tos;

- móvel de aço ou madeira usado para guardar documen-

- parte do edificio onde é conservado o patrimônio documental de uma instituição;

- órgão governamental criado com o fim de guardar e conservar a documentaçâo de um país, Estado ou município;

- conjunto de documentos e, finalmente,

- títulos de revistas ou periódicos.

Para os que se dedicam às atividades arquivísticas, arquivo passa a ser o próprio material, isto é, o conjunto de tôda a documentação produzida e recebida por uma instituição pública ou privada, no decorrer de suas atividades. Pela conceituação antiga só era definido como material de arquivo aquêle que servisse para estabelecer ou reivindicar direitos; só se acentuava o aspecto legal. Depois, quando já se tornava inútil para tal aspecto, o material era encaminhado para os museus e bibliotecas. Todavia, como vimos, o destino dos arquivos é passar por lenta evolução; diminuindo $n$ valor administrativo e aumentando a sua importância como documentação histórica; são sempre arquivos em processo de transformação. Os arquivos históricos de hoje foram arquivos administrativos de ontem e vice-versa. Modernamente Solon J. Buck, arquivista americano, definiu arquivo como o conjuntn de documentos e papéis oficialmente produzidos ou recebidos por um govêrno, organização ou firma e conservado por si ou por seus legítimos sucessores para efeitos futuros.

Arquivar, portanto, será guardar e conservar documentos e por decorrência arquivo será o local onde se guarda e conserva um patrimônio documental.

Com a evolução das técnicas arquivisticas, sobretudo em meados do século XIX, foram determinados alguns principios cuja aplicação, hoje universal, visa tornar mais racionais e seguras as atividades num arquivo. Dêstes, dois são principais: o "respect des fonds" que proibe aos arquivos gerais a mistura dos materiais das diferentes agências criadoras e o princípio de "provenance", segundo o qual tôda a documentação deve ser guardada na ordem em que foi criada. Antes da implantação de tais principios, os arquives eram considerados coleções de documentos e o 
material, escolhido entre numerosos maços e arranjados cronològicamente ou por assuntos, servia somente a determinados interêsses; quebrava-se, violentamente, a constituição da formação do material dos fundos.

Quanto as suas funções e importância, já tocamos levemente no assunto anteriormente. De início destaca-se a utilização administrativa; depois será caracterizado como fonte histórica por excelência e, além disso, grande significação têm os arquivos sob o ponto-de-vista jurídico, social, pedagógico etc.

No estudo de suas divisões podemos enquadrar os arquivos em vários tipos. Uma primeira classificação, adotada nos cursos do Arquivo Nacional pela professôra e renomada técnica Da Maria Luiza Stallard Danneman, agrupa os arquivos, segundo a agência criadora em: arquivos públicos, institucionais, comerciais e pessoais ou familiajs. Os arquivos públicos podem ser: federais, estadtais e municipa:s. Ainda os arquivos federais podem ser centrais e regionais. Os arquivos institucionais serão provenientes de instituições educacionais, igrejas, corporações não lucrativas, associações, sociedade etc. Os comerciais; firmas, corporações, companhias. Finalmente os arquivos pessoais ou familiais são organizacios por particulares e integram o patrimônio familiar.

Outro critério de divisão de arquivos é aquêle que se baseia na documentação ainda usada correntemente ou já solucionada. Teremos aí o arquivo chamado ativo, corrente, de movimento ou vivo e o arquivo inativo, permanente, também chamado de custódia ou, mais vulgarmente, arquivo morto. Finalmente grupam-se ainda os arquivos em: gerais, quando concentram tôda a documentação da instituição ou arquivos especiais quando atendem a parcelas determinadas desta mesma instituição. Relativamente aos arquivos especiais e gerais, os primeiros são constituidos pelos conjuntos de documentos guardados e movimentados nos diversos setores em que se acha desdobrada a entidade e sua intensa utilização determina a conservação junto aos diversos serviços que dêles dependam. $O$ arquivo geral, pelas suas proporções, representa a memória de uma organização, sendo responsável pela manutenção do acervo de papéis e documentos criados por tôda a instituição. Funciona, portanto, como arquivo corrente e como arquivo de custódia. Já o arquivo corrente é caracterizado pela circunstância de a documentação ali conservada ser consultada e estudada freqüentemente, eis que se tratam de assuntos não solucionados ou que, por terem sido liquidados em época recente, devem permanecer naquele arquivo. Findo um determinado periodo, a documentação é recolhida para o arquivo de custódia, onde se depositará durante um prazo legal - fixado pela seção de origem - enquanto oferecer efeitos relativos à defesa de direitos ou esclarecimento de assuntos de relevância. 
Esgotado êsse período, uma comissão especialmente constituída, após racional e minucioso estudo, decidirá - caso a documentação não apresente motivos importantes que justifiquem a sua conservação - se ela será remetida ao Arquivo Nacional (para utilização histórica futura) ou incinerada.

Para exata compreensão dos têrmos empregados na arquivologia, deve-se ressaltar a atuação do Conselho Internacional de Arquivos, que tomou a seu cargo a coordenação da terminologia. Todavia, a questão requer estudos minuciosos e os resultados dos trabalhos ainda não foram divulgados.

Vinculando-se diretamente com a ciência da administração $e$ com a história, de vez que por definição acham-se os arquivos postos à disposição de tais matérias, com elas, evidentemente, mantêm relações as mais estreitas. Acontece, contudo, que nos arquivos se acumulam conhecimentos pertinentes à vida em geral. Por isso mesmo, o material dos arquivos serve pràticamente a todos os ramos do conhecimento humano. Mais particularmente, constitui o laboratório de trabalho de disciplinas como a paleografia, a diplomatica, a cronologia, tôdas três auxiliares indispensáveis dos estudos históricos.

Reservamos para o ilustre especialista que nos sucederá em breve o esclarecımento sôbre a documentação e seu campo. Um papel de suma relevância é reservado aos arquivos. Constitui um dos principais setores de qualquer serviço ou centro de documentação. Permitimo-nos, porém, algumas considerações ligadas às bibliotecas. Embora semelhanças notadas entre elas e os arquivos, sobretudo porque ambas se desenvolveram paralelaménte, não devem os serviços destas importantes instituições culturais serem confundidos. "A aplicação de critérios bibliotecários para n manejo de materiais arquivísticos teve, em muitos casos, fatais conseqüências para a ordenação orgânica dos fundos documentais." $\left({ }^{9}\right)$ Afora as distinções intrinsecas que não compete aqui enumerar, há cutras de caráter politico que vêm sendo exercidas ate hoje e relegam os arquivos a uma condição de primo pobre. Muitas foram as administrações de vista curta e deliberaçóes igualmente miopes que, ao invés de garantirem condições mínimas de funcionamento aos arquivos a seu cargo, evitando que se deteriorassem em galpões ou porões impróprios, trouxeram ainda uma interpretação muito singular sôbre material de arquivo e para lá encaminharam os funcionários inúteis e até prejudiciais em outras seções, os desequilibrados mentais, os temperamentais e igualmente os servidores-problemas. Por outro lado, mereceram os bibliotecários os benefícios dos podêres públicos, principalmente consubstanciado na regulamentação profissional e no estabelecimento dos aúcleos de formação enquanto o pessoal dos arquivos

9 - George S. ÜlibarRI - op. cit. 
foi abandonado a sua própria sorte e suas funções desamparadas pela lei e rebaixadas a niveis em nada condizentes a sua importância e responsabilidade. O preparo dos arquivistas em nosso pais acha-se reduzido a um insignificante número de iniciativas, dentre as quais o curso ministrado pelo Arquivo Nacional, em caráter regular, com matérias de nivel universitário, mas sem a expressão e o reconhecimento que lhe são devidos. Acrescente-se ainda as aulas de técnica de arquivos dos cursos promovidos pelo DASP. Por isso mesmo acham-se os arquivos brasileiros, de uma forma geral, entregues a um pessoal sacrificado, que compensa com boa vontade e muita improvisação a ausência das informações especificas e indispensáveis ao eficiente exercício de seus misteres.

Não comentaremos, por fugir às finalidade dêste Encontro, os itens 2 e 3 . Apenas, para informação, ressaltamos que um dos grandes, e talvez o maior, dos problemas com que se defrontam os arquivos na atualidade é representado pelo aumento vertiginoso da documentação, congestionando excepcionalmente as sempre repletas dependências dos arquivos. Dentre alguns fatôres que explicam tal crescimento extraordinário alinham-se a expansão acentuada das atividades governamentais nas últimas décadas, a ação dos governos interferindo em setores anteriormente próprios às iniciativas privadas e também o aperfeiçoamento técnico, contribuindo para a maior produção documental. Justifica-se a atenção dada às operações de expurgo e eliminação de material, um dos capítulos mais importantes da arquivologia pelas suas conseqüências e que requer sólidos conhecimentos do arquivista encarregado, pois êle é homem que sabe destruir.

$\mathrm{Na}$ história dos arquivos merece enfoque os tempos modernos. Sobretudo - por absurdo que possa parecer - têm os arquivos se beneficiado das ações revolucionárias, não obstante as perdas materiais sofridas. Com a Revolução Francesa, ignorando totalmente as instituições do passado, permitiu-se, naquele pais, a primeira centralização moderna de arquivos. Constituiram-se os arquivos nacionais a partir do núcleo de papéis da Assembléia Constituinte, aos quais foram reunidos os documentos dos arquivos dos Conselhos e das grandes administrações do Antigo Regime c, ao mesmo tempo, acrescentaram-se os arquivos das abadias, conventos e igrejas de Paris e aquêles dos particulares emigrados ou condenados. Pela primeira vez, também, um plano tão considerável se estendia aos arquivos de todo um regime político, administrativo, feudal e religioso ao ponto de substituir, de um golpe, a noção de "arquivos de Estado" pela de "arquivos de um golpe, a noção de "arquivos de (ex.: a destruiçâo de do-
nacionais." Afora os titubeios e erros (ex)
cumentos fertdais considerados inúteis) foi uma contribuição inestimável da Revolução Francesa e sòmente a legislação soviética 
de 1918, concebida racionalmente à luz de tal experiência pode lhe ser comparada. Foi nessa época proclamado um principio fundamental, revolucionário: os arquivos pertenciam à nação, devendo ser colocados à disposição de todos os cidadãos. Assim o princípio da publicidade dos arquivos se substituiu àquele do segrêdo de Estado. Posteriormente a arquivologia foi se enriquecendo através de contribuições de alto valor para elaboração de uma doutrina cada vez mais completa. Atualmente nossa concepção de arquivos está bem longe daquela das gerações precedentes. A legislação soviética de 1918 1941, a criação dos Arquivos Narionais de Washington (1934), enfim a evolução considerável dos arquivos franceses e inglêses, após a Segunda Guerra Mundial, introduziram modificações muito profundas na estrutura $e$ no espírito mesmo dos arquivos. Hoje em dia não se pode conceber um Estado moderno sem uma rêde organizada de arquivos que recolha a massa de papéis públicos e a organize para pôr a documentação assim reunida à disposição das autoridades e que ao mesmo tempo funcione como centros privilegiados de pesquisa histórica nacional. Assiste-se ao nascimento de arquivos centrais em um grande número de países que não os possuiam ou a reorganização completa dêsses arquivos. Verifica-se, então, a instituição de uma autoridade arquivistica central. Apenas tornados independentes os Estados estruturam uma organização arquivistica. É o caso da India, Israel, Gana, Tunisia. Um esfôrço mais gigantesco ainda está em curso, presentemente, na República Popular da China que, há poucos anos atrás, não possuía nem mesmo um embrião de arquivos centrais ou provinciais. A obra desenvolvida na India é igualmente notável. E assim em diversos outros paises novos ou em fase de reorganização após o tumulto da guerra. $\left({ }^{10}\right)$

No Brasil verificamos também e finalmente os reflexos de uma nova ¿ pujante mentalidade mundial para o trato dos arquivos. Como primeira providência estrutura-se o Conselho de Administração de Arquivos, subordinado diretamente ao Sr. Ministro da Justiça. Estarão, certamente, nossas autoridades, que em tă boa hora se voltaram para o assunto, cientes de que a iniciativa sòmente atingirá suas elevadas finalidades se recrutar pessoal técnico para a composição do nôvo órgão, vedando, enèrgicamente, os critérios de indicação política.

Outra medida oportuna foi a regulamentação da microfilmagem de documentos oficiais, um passo à frente no desentrave de obstáculos ao desenvolvimento.

10 - Robert-Henri Bautier, "Les Archives" in "L'Histoire et ses méthodes" - Encyclopédie de la Pléiade - Librarie Gallimard - 1961, páginas 1.132/1.137. 
Aguardamos, agora, uma lei que implante um Sistema $\mathrm{Na}$ cional de Arquivos. A idéia já é velha e existe até um magnifico anteprojeto de lei elaborado por Comissão instituida em Portaria $n^{\circ}$ 316-B, de 7 de novembro de 1961, do então Ministério da Justiça e Negócios Interiores e composta por elementos da mais alta expressão e competência. Com êste instrumento o govêrno estarja capacitado para intervir na solução de problemas dos mais significativos dentre os quais a salvaguarda de um patrimônio histórico de valor incalculável e insubstituível, o incremento da pesquisa cientifica como condição para o progresso, a uniformização de orientação técnica em matéria de arquivos, o intercâmbio e a assistência para os arquivos estaduais e municipais, o esvaziamento de nossa documentação com a aquisição, por países estrangeiros, dos arquivos particulares de personalidades públicas, o preparo de pessoal especializado em níveis universitários como já ocorre em outras nações etc.

Para concluir, porque plenas de conteúdo e oportunidade, citamos as palavras do insigne historiador José Honório Rodrigues: "não há reforma administrativa sem reforma do sistema de arquivos" e "não há desenvolvimento econômico sem arquivos eficientes." (11)

11 - José Honório Rodrigues, Nota Liminar no livro de T. R. Schellenberg - "Documentos Públicos e Privados: Arranjo e Descrição" - Arquivo Nacional, Rio de Janeiro, 1963.

José Pedro Esposel - Do Banco Central e Diretor do Instituto de Ciências Humanas e Filosofia, da Universidade Fluminense. 